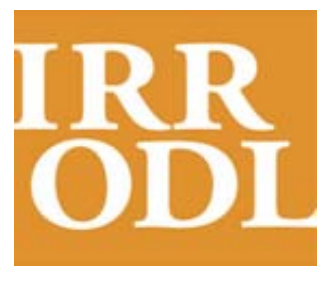

International

Review of

Research in Open

and Distance

Learning

Vol. 12.2

February - 2011

\section{Delimiting the Prospect of Openness: An Examination of Initial Student Approaches to E-Learning}

\author{
Christopher Naughton and Juliette Smeed \\ New Zealand Tertiary College
}

John Roder

University of Auckland

\begin{abstract}
When converting from a paper-based distance mode to an online mode of teaching, certain expectations arise that students may engage not only in the development of extended research activity but that the quality of discussion and thinking will change. With access to open-ended discussion within the online forum the opportunity is afforded to students to share ideas and in turn develop their shared knowledge, a facility denied to them when in the paper distance mode. However, in a recent study conducted in New Zealand, it was shown that despite having access to online forums students moving to an online platform refrained from participation in this social exchange. A possible explanation for this indifference was thought to be the students realising that the online exchange made no impact on their assessment. Hence, the collaborative rhetoric of Web 2.0 made little impact when the summative evaluation remained unchanged from previous paper-based assessment. This paper reports on the introduction of online learning at a private tertiary college in New Zealand and describes the response of students who found difficulty in reconciling a community of learners and openness within what was perceived as an evaluation that remained individualistic and competitive in nature.
\end{abstract}

Keywords: Online learning; strategic learner; dialogue; discussion forum; Web 2.0; affordance 


\section{Introduction}

This paper arose from a two-year longitudinal study of staff and students as they changed from a correspondence, paper-based course to an online provision. Prior to full implementation, two pilot studies were undertaken with sample groups of students who volunteered to complete their programme in the online environment. This paper reports on the second of the two studies undertaken in 2008-2009. The students were based in New Zealand and were all early childhood student teachers taking a six-month degree upgrade. The object of this study was to examine the student teachers' reactions to the new learning environment and their ability to make use of the discussion forum allocated to them for the duration of the course. Among many diverse findings, the student interviews revealed a significant number who appeared to be strategic in their approach to learning. The term strategic, in this paper, is similar to the term used by Marton and Säljö (1976), Entwhistle (1981), and Biggs (1993), for whom a strategic learner is seen as impersonal and working at a surface level. In this paper strategic learners are also characterised as looking for the most expedient way to complete coursework and showing deference to what was said or written by the college tutor and accepting whatever advice was said or written by the tutor; whereas learning that implies sharing, not being recognised as merely "getting the job done,” is regarded in this paper as the most important aspect of studying.

This strategic approach, where knowledge is seen as there to be appropriated or consumed, appears to have little in common with the current Web 2.0 concept of learning. The fundamental of Web 2.0 (see O’Reilley, 2009) is that knowledge is created and validated through shared dialogue (Dysthe, 2007). Learning in Web 2.0 is also seen as emergent as ideas are developed through acts of shared thinking (Lave \& Wenger, 1991). Shared ownership of learning in turn becomes the antithesis of the "strategic" worldview, wherein sharing is seen as non-productive and learning is regarded as the appropriation of knowledge as private property. Knowledge in this sense becomes a commodity, an entity which is static and unchanging, acquired through individual enterprise. Once gained, knowledge has to be protected and removed, so others don't gain access. This view of learning seems to typify aspects of the strategic learner in Biggs (1993), for whom knowledge remains impersonal and at a surface level. In relation to this study, the irony of the strategic approach was that the students whose daily work in early childhood education was characterised by sociocultural principles of learning, similar to those of Web 2.0, did not develop themselves in a similar manner while studying at their own level. Even though the opportunity was there for students to engage in a form of social learning in the discussion forum, a fundamental in Web 2.0, they chose not to engage and not to recognise the learning space, or discussion forum, as a potential community.

An attempt to bridge this divide between assessment and appointed tasks that are more open and democratic in nature has been proposed by Biggs and Tang (2007). The emphasis on the intended learning outcome is mitigated in their study by the inclusion of teaching learning activities that align with the assessment tasks. The concept is highlighted by providing students the freedom to select activities that are open in nature with the opportunity to reflect on the ideas presented in the coursework and a choice in how to develop an overall educational focus for activity rooted in practice. The students were, in the study reported on by Biggs and Tang (2007), asked for 
complete journals that could be read and discussed to see how, or if, they could provoke changes in practice. With increased response and better marks being achieved, this would indicate that the approach was a success. Named constructive alignment, this approach seemed to hold promise for online learners. Although the reconfiguration of a hierarchy still remained in assessing students' work, this approach seemed to go forward in aligning tasks and observing constructivism as a basis for learning at tertiary level. It was this openness in approach to learning and sharing ideas that was sought in the project being reported.

This paper begins with an acknowledgement of several leading figures in the world of Web 2.0, and outlines their thinking, in relation to the shifts in learning patterns brought about through the development of Web 2.0 technologies. The practice of refining attitudes towards learning is further considered before reference is made to the project environment under discussion. This project was titled the Web-Enhanced Digital Learning or WEDL project. The study had no preconceived idea as to the outcome, and the strategic learner was a discovery that was made through the grounded approach to the data gained through interviews and analysis of the discussion forums with staff and students.

\section{Learning in the Age of Web 2.0}

With access to the Internet becoming more freely available, new challenges have arisen for teachers and students (Roder \& Hunt, 2009). The ease with which information can be obtained and online dialogue engaged raises many questions as to how this influences teaching and learning. Can tertiary institutions continue to provide courses and teaching structures as they did prior to the advent of online learning, or must they adapt to the new learning environment? Instead of being primarily purveyors of knowledge, should institutions become places for the exchange of ideas as in Web 2.0 philosophy (Siemens, 2008)? With information so freely available, does open access learning, which includes discussion, need to offer more than information supplied in neat parcels such as study guides? Should knowledge and knowledge acquisition be reconceptualised in the new online learning environment?

Commentators have suggested that owing to Internet accessibility there have already been changes in the nature of our relationship to information and society (Castells, 2000: Fisher, Higgins, \& Loveless, 2006: Lankshear 2003: Roder \& Hunt, 2009: Siemens, 2008). The argument is made that there has arisen a shift away from controlled teaching to a greater sense of governance being exerted by the learner. This implies students making decisions over the content and their level of interaction with other learners no longer being confined by the classroom or the knowledge boundaries set up by the institution (Siemens, 2008). For some, the impact of the communications revolution implies that knowledge can no longer remain unquestioned. Knowledge is instead seen as in a state of flux (Kress \& Pachler, 2007), where ownership is produced through interaction between authors. Aldrich (2009) adds that online learning is an opportunity to "unschool" students and create a meaningful, wider sense of ownership. This wider ownership would allow students to develop a sense of shared knowledge to replace existing ideas of scholarship as fixed and immutable (LaPointe \& Gunawardena, 2004). The development, in other words, of a "Web 2.0 mindset" may be more important than being in possession of 
prescribed facts. This debate about information and learning, which can be traced back to Illich's notion of deschooling (Illich, 1971, 2000), implies students being critical, discursive, acquisitive, position taking, and open to new ideas (McWilliam, 2005). For students in a critical thinking community, the interactive experience becomes a recognised part of what Bauman describes as the unlearning process (Bauman, 1993). This broad definition of learning is seen to have a significant impact on students sharing ideas and gathering knowledge in a more informal context (Gulati, 2004). These characteristics of the learner as open, engaging, and willing to discuss and develop new thinking was the hope of the WEDL research team.

The five stages of initiating students into the online environment advocated by Salmon (2000) provide a support through which students can be initiated into the new environment. As the students grow in technical accomplishment and confidence in the use of online provision, together with support from the moderator, Salmon suggests that at stage five students can achieve wholehearted engagement, becoming fully responsible for their learning using their personal experience in developing their exploration of a topic or area being studied. It is at this point that Salmon suggests the moderator leave the discussion. However, despite Salmon's and others' models for learning online, the potential for radical change in the learning is often undermined by summative assessments, designed to meet learning outcomes rather than focus on the processual and discursive aspects of learning such as the discussion and development of ideas. The resulting prioritization of assessment reduces the scope of learning online. Openness challenges the institution and threatens the privileged status of the textbook or study guide. However it is the concern of the Web 2.0 educator to achieve learning with reference to potential learning outcomes (Davis \& Sumara, 2006). For Siemens, learning within a Web 2.0 environment is one that permits learning to become the "creation and navigation of networks" (Siemens, 2008, p. 8). Students who are able to self-regulate develop their learning in a fashion of their own making, which reflects their ability to manage networks that they have constructed. In this way the role of the online provider is one of extended teaching, embracing the network, and enabling connectionforming relationships (Driscoll, 2000; Downes, 2010). The role of the provider as a space for research is considerably advanced in this instance as an active connector to faculty becomes another aspect of networking. Structured modules such as study guides are not, therefore, to be removed, but less structured ways of working are provided, letting students take advantage of the new learning environment while still observing practical competence in any vocational field. Education is thus concerned with learning how to share information, and seeing oneself as a learner within a human endeavour of seeking change, in advancing the needs of ethical living (Lave \& Wenger, 1991). While these aspirations were held in relation to the ambition of Web 2.0 implementation, the project had less ambitious goals and was intended to open to the students an opportunity to work online with tools provided as in Web 2.0 platforms but without a specific grounding in Web 2.0 as a philosophy of learning.

\section{Background to the WEDL Research Project}

The students selected for the WEDL project were 21 early childhood student teachers who had completed a Diploma in Teaching at a private tertiary college prior to undertaking the six-month upgrade to a degree. The upgrade programme became the basis for this research project. The 
student teachers, who were all working in early childhood centres, ranged in age from early twenties to early sixties. The students came from all over New Zealand. Only a few had met any of the college staff on a face-to-face basis. Some had completed their diploma as class-based students, while most had completed their diploma in a paper-based distance-learning mode, and others had experienced a combination of both field (evening class-based) and distance learning.

The research method involved students and staff in a constructivist grounded research approach (Charmaz, 2005). In practice this study involved individual interviews with students on two occasions as well as two focus groups and two individual interviews with the staff. The students were interviewed by phone for half an hour after five weeks in the online programme and again at the end of the six-month programme. The premise was that the first interviews would generate themes for analysis and coding that could, additionally, inform the approach for the second interviews. Students were prepared for online study through a series of tasks that together constituted a non-assessed orientation course. In preparation for the online discussion forum students were shown how to make an entry and how to follow discussions on the forum pages. The nature of the student preparation was to ensure that the learning platform that they were to use was well understood and that they had some experience of exchanging information about themselves in the forum prior to the course commencing. This warm-up period, similar to the first two stages in Salmon's model (2000), lasted for three weeks, with online and telephone support being offered to the students as well as a designated member of staff acting as course moderator. The discussion forums lasted for the duration of each course, which was up to a month. The exception was the research course, which lasted for the whole of the six months. The expectation was that students would make at least two postings for each course, and while many did far more, some were unable to keep up with even two postings towards the end of the course. The staff attended a pre-commencement series of workshops, which were video-recorded and reported on as part of the study. These workshops once again focused on gaining a good understanding of the tools provided. These included how staff could gain access to the students' online discussion forum, add anything to that forum, and access online assignments, mark, and return those assignments online.

Each interview was audio-recorded digitally, including phone interviews with students and staff focus groups. The recordings were sent to an external transcription service, where they were transcribed. The recordings and transcriptions were then returned as electronic typescripts of each interview. The interview data was coded and analysed using Weft free domain software.

\section{The First Round of Student Interviews}

The student interviews were semi-structured to allow the interviewers - three researchers based at the private tertiary college - to ask supplementary questions if there appeared to be more information forthcoming from the student interviewees. The questions included reference to students' past experience of working online, the expectations students felt that the college had of them, the value of the discussion forum, and how they felt about the forum. It was only after the first set of interviews had been completed that themes for coding the data were identified. It was at this point that strategic approaches to the course started to become evident. 


\section{The Forum}

Before reporting on the interviews it is valuable to consider for a moment the role and nature of the exchange in the discussion forums that the students engaged in. Throughout many of the online forums, each separate course having a four-week forum, the exchange was characterised with a great deal of well-wishing and support. This sense of camaraderie was encouraging for the early stages of the project. However, after a period of time and at the request of the research team, "ethical dilemmas," after Dysthe (2007), were posted for the students to consider. These proved popular, the hope being that students would engage with the text and that they would develop their ideas. A critical engagement was not anticipated as follow-up readings to the ethical dilemmas were not provided and the availability of posting web links was not considered or provided for. There was, however, in the research forum a sense of opening up and discussing ideas. The discussions were mostly on the choice of topic for the research paper and the difficulties that were being encountered in undertaking a research project. (It should be added that the students had to undertake a 3,500-word research project, of their own choice of topic, as part of the coursework.)

\section{Getting the Job Done}

At the outset what marked the strategic students was their preoccupation with isolating only what "had to be done." This was exemplified at the start of the orientation course, where the tutor was constantly asked about what counted and what did not count towards their marks. Some of the students expressed a need to know exactly what was being assessed during the orientation even before the course had begun:

Student: Are we meant to do all of those little things?

Researcher: I think it's good. I can't say no.

S: We don't get them marked do we?

R: Not that first course, no.

$\mathrm{S}$ : But the other ones?

This exchange exemplified the attitude of needing to know the strategic value of any contribution. First encounters with the discussion forum also saw students asking if they had to answer all the posts by other students. While the query can be partly explained by the novelty of the online mode, using the tutor to clarify what gets marked in an orientation course suggests a strategic preoccupation.

After five weeks the students were asked in the first interview what value they saw in the online discussion forum. Some of the students answered by saying that time was a big factor in being able to discuss their work with other students in the forum:

I know I want to be an active part of it. I know what I have to do; it's finding the time to be completely involved in it at the 
moment. I might flick in during the day and read the discussions but you know, as people keep telling me, I've got a lot on my plate so my main focus is to get the assignments done and in. (Student, 2009)

Since many of the students were working full-time, it is understandable that prioritising how they spent their time was an important influence on their participation in online discussions. Another student experiencing similar difficulties with time and priorities clarified her attitude with additional comments:

Yes it depends what mood I'm in. I think it's great, you know, people ask you for readings and that but sometimes it's like I haven't got the time. I'm so busy trying to get everything done that I've got to do instead of trying to help someone out, or trying to go through all my readings, but then I know - that's what we're supposed to be doing. (Student, 2009)

Both students appear to want to be a part of the discussion forum, but multiple demands on their time cause them to approach it strategically by distancing themselves. The second student clearly viewed participation in the discussion forum as a duty to the college and a service to other students, rather than as a contribution to her learning. However, she also acknowledges that "... it's great . . . people ask you for readings," which is a recognition of her valuing being seen as part of the group, an interesting admission and one that will be revisited later in this paper.

\section{Valuing the Tutor}

A tendency to revere the contribution of the tutor often appeared in the interviews. One student reported,

Whenever I go on the discussion forum I always search down and look for a lecturer's name so I go for lecturers more than the students. I mean I do read it all when I expand the text but I look for their notes. I know that's sort of like gospel. It's the right one. They know what they're talking about. (Student, 2009)

For this student, the discussion forum did not in any way disrupt traditional concepts of a tutor's authority; it merely necessitated the development of new practical strategies for locating that voice. This attitude may well have inhibited the discussion as the strategic students often emailed the tutors directly. When tutors responded to a one-to-one e-message, students were again in effect acting strategically by avoiding the discussion. When the tutor's ideas are considered the most important, there is a danger that student contributions to the discussion will remain at the level of requests for clarification or confirmation of "rightness." 
Another student's response as to the experience of the discussion forum showed her to be in a stage of adaptation to the new facility:

Researcher: How has it helped you?

Student: Sometimes I try and get ideas for things, like everyone says pretty much different things so they all help you to think what you want to do, like the resources page everyone is giving different ideas.

R: How are you finding that, how are you finding the discussion forums?

S: It's quite good. Sometimes I think there's so much to read on there whereas maybe I should spend that 20 minutes getting into my reading. Then of course there are the six messages, you've got to read-you want to know what they say. To start with there was quite a lot on.

Here we find a student weighing up the benefits and potential distractions of the new mode. Curiosity about the various contributions of the other students and recognition that there is valuable information there appear to compete for the time allocated to traditional learning tasks. From a Web 2.0 learning perspective it is interesting to see the student talking about "different things" on the resources page, where readings and reflections were left by the students for each other. Could this be seeing learning in a broader light than the supply of the right answer to a specific question?

Another student saw the discussion forum as a way to clarify her previous work rather than to share or develop anything:

Usually I will read a lot and finish the entire study guide and the readings and I take some notes and then I start doing my assignment. Only when I have a question will I ask people for help and join the discussion forum. I probably do it all myself. (Student, 2009)

The approach of using the discussion forum to get help and collect information was a common feature of the student interviews and could be seen as strategic. Another response to this approach to the forums was,

Yeah you take on board what you want and you leave out what you want to leave out. I found it really helpful when the tutors clarified points or if people put up the questions for the discussion and others started giving their answers. Sometimes people were getting way off track and the tutor would come in and just clarify more clearly what they want actually answered. I found that helpful. (Student, 2009) 
Having information or questions come in from various contributors provides one recognised benefit for this student's learning, but the greater benefit is having that information subsequently controlled and valued by the tutor. This seems to be a missed opportunity, where student's dialogue could have been fostered only for the tutor to make a ruling. A more widespread tendency for students to view participation in the forum exclusively in terms of giving or taking is also evident in this quote. For the student quoted below, the discussion forum served little or no purpose, although she could see the benefit it provided for others:

For me they didn't seem useful because I participated because I had to, not because I needed to. I can see how for other people it could be very helpful and I did see other people posting things and questions and bouncing ideas off of each other which obviously was a good idea and it assisted their learning. (Student, 2009)

There is something quite wistful in this response, a sense, perhaps, of what has been lost through this adopted strategic approach to her learning. It is interesting how again the interaction is recognised as positive learning but seen as something that "others" do. It is interesting to look at the language of learning. She states that she had to participate so she did, but that the students in their own space were bouncing ideas off each other. One is very didactic, seeing learning as having to, whereas the student-to-student activity was bouncing off, a much more light-hearted description and something that they do. It is almost a vision of sitting indoors while watching others play outside as her self-imposed vision of learning activity is one of being removed from a community of learning.

\section{The Second Round of Student Interviews}

When the second interviews were held at the end of the six-month course, it was plain that many of the students still held unchanged attitudes towards the discussion forum. Participation at a minimum level was still the accepted approach for the strategic students:

Basically at the end of the day you're going to do what you're required to do to get through as much as it is a requirement to enter into it, they would do the bare minimum and then that's it. (Student, 2009)

Again the strategic student switches from the first-person I statements to the third-person they. By omitting themselves from the answer a way is found to justify a position. It is not "just" the person speaking who does this, so it is okay! Another student remarked, "Just getting it done, and in on time ... you know, studying for me was more about getting the essays done” (2009). This represents a more typical strategic perspective. 
When students were asked how helpful the course study guides had been, the responses to the Research Study Guide were particularly mixed. This course relied heavily on the students' ability to devise their own project and was the least prescriptive of the study guides. The strategic response was very clear:

The only Study Guide that I didn't find helped me was the investigation (Research). I think it was hard because they couldn't write a Study Guide on every single area; you had to choose your own area. So that was the one that I didn't find useful. (Student, 2009)

This student's attitude can be linked to that of another student, explaining why the study guides suited her:

I suppose it does depend on the person. For me I think they were quite good-to just be given things. Otherwise if I chose things, I might you know choose stuff that I maybe already knew about already. Otherwise I might choose something completely different that I think that I should know about but at least if I got given something that I have to actually do, that specific thing makes it easier. (Student, 2009)

The last response is interesting as the student readily admits she could seize the opportunity and write about something she may have already written about. The next statement sees the student considering making a different choice about "something completely different that I think I should know about." This might be a genuine interest and shows a readiness to try something new. However, this thinking is then dispelled as she sees the easier option being to do something that is a given, as in following the study guide. Again, as in the first series of interviews, students spoke of being overseen by tutors in the discussion forums as a good thing: "I think he [the lecturer] is doing wonderful. What he put on there last night actually made me stop and think! His comments were really good” (Student, 2009). Perhaps what was needed was less tutor input and more emphasis on the student potential so that they might validate their writing and their voice and pay less heed to the tutor. 


\section{Getting the Job Done}

A development in the strategic approach saw one student considering participation in discussion forums as compulsory:

I think it would be a good thing. I think it's all very easy (as it's not part of the assessment) not to do it. To sit back, and take all that other people have said and think, "Yes I'll use that," and not actually put your input into it. I think if it was part of the assessment that you would then look at it in a different light and think, "Well actually I need to contribute, this is part of my assessment, and I need to think about what I'm going to help the others with.” (Student, 2009)

The statement above might indicate confusion on the part of the student as to the role of the discussion forum in her learning and whether participation is a matter of giving or taking, helping others, or developing her own thinking. Once again the third person is evident as the student describes contributions to the discussion forum being something "you would look at in a different light."

Some students expressed anxiety that others poached more than contributed ideas. This brought up issues of knowledge acquisition versus knowledge sharing, as one student explained:

There was one discussion that I put on something about transition to school. I said too much, because a few people later said, "That's a great idea I might do the same as you." I'm thinking, "That's not what it's about." I got a little bit peeved with that so, I've changed my topic. I thought people took it a bit too far, I mean too much information can be shared. (Student, 2009)

Another student was less circumspect: “I'm very cautious about what I write on there. I just don't want people to steal my ideas” (Student, 2009).

Neither student demonstrates an understanding of the value that may be gained from sharing and exploring ideas together. Additionally, the accusatory way of speaking about other students in the same cohort suggests a very strategic approach to knowledge. This lack of knowing and sense that sharing is copying suggests a lack of trust in how students are working with each other. A discussion of this approach may have been useful as a topic early on in the forums to challenge these ideas. 


\section{A Summary of the Student Interviews}

The interviews revealed much about how students felt about their study. Above all, it was clear that an exploration of ideas beforehand, concentrating on the rationale behind the discussion, was required. Undertaking an exchange on knowledge as property to be acquired or knowledge as something that was developed through dialogue might have helped in alleviating student anxiety that they had to "protect" knowledge once gained. While some of the students recognised the learning potential of online discussion forums, other students were not clear about the concepts of sharing in a learning community. How the exchange of knowledge worked in the online discussion also appeared to be poorly understood. Knowing what to do in an online environment will be discussed in more detail in the section following a review of the staff response to strategic approaches adopted by the students. The role of the tutor was another topic that might have been valuable to discuss. Where once knowledge was to be parcelled out, discussing the role of a tutor in an age where knowledge is far more accessible would have been enlightening for the students and a useful opportunity for them to have expressed their own opinions.

\section{Interviews with Staff}

Three full-time members of staff were interviewed in focus sessions and individual interviews at the start and end of the project. Questions were again set within a semi-structured framework to allow the interviewer to ask supplementary questions if required. The interviews were again coded and interpreted within a constructivist grounded framework (Charmaz, 2005). The use of the grounded approach implied that the information gathered in the first interviews was subsequently thematised and provided the focus for the second round of interviews. In addition to developing a set of themes, the answers given by the students and staff in the first interviews were, in line with the disclosed themes, used to generate questions in relation to their first response.

The three staff members who acted as online tutors were provided with extensive preparation for online teaching experience, including technical support and mock discussion forums that they had to supervise. Interviews conducted at the end of the professional development phase revealed that tutors considered the discussion forum useful for a variety of reasons, including developing open discussion, clarifying assignments, having opportunities to ask more in depth questions, and creating a sense of trust. The tutors felt that students had to undertake background reading on a subject in order to be able to discuss it in the forum; therefore, it was important to encourage students to undertake the course readings first. The student experience was seen as getting through a crisis of confidence after the reading stage. As to the discussion forum, this was envisaged as a space where the students could clarify their ideas after having read on the subject. Ideally, staff wanted students to develop the ability to comprehend readings online so that tutors could "get them to think how the readings relate to the assignment" (Tutor, 2009). The online discussion was seen as having little or no consequence if the readings hadn't been assimilated. One tutor suggested, 
The whole point of being here is to express your point of view, but also being open to persuasion by someone else's point of view or by someone else's perception-I suppose that's where the dialogue comes in. (Tutor, 2009)

In relation to the discussion forum, staff clearly saw the need to direct students: "If you go into a lesson without a clear objective and without a clear plan of where you want to be and how you're going to get there, you won't end up anywhere” (Tutor, 2009). When further questioned whether there was a link between theory and practice, the tutors appeared to hold a view of theory as unquestionable and unchanging, and therefore a reliable guide for students. Hence understanding and developing a familiarity with readings was integral to any learning process. Study guides and learning objectives were seen as valuable ways to organise the course, especially for English as a second language (ESOL) students. Frequent references to the classroom also suggested the carryover of traditional teaching and learning beliefs, such as learning having a predetermined direction that was contained within a discrete structure (Siemens, 2008). When asked, at the start of the research project, how to advise students embarking on their first online learning experience, one tutor stated:

My advice would be think of it as a classroom, like they were walking into a classroom, yes it can be scary but if they go in there willing to try something new and learn different things and interact with these people in different ways then I think anyone could do well. (Tutor, 2009)

\section{Staff-Student Experience and Web 2.0}

Reflecting on the tutors' responses, the principle of an open learning experience, where students are seen as experts in their own right, co-constructing meaning, seems at odds with the approach of the strategic learner (Kress \& Pachler, 2007). However, use of the schoolroom metaphor (see Siemens, 2008) to exemplify an online forum indicates a lack of awareness by staff of the extent to which past structures influence their work with students in the online environment. Staff also felt that the study guide lent coherence and strength to the learning process, especially for the ESOL students. What is not recognised is that student ownership of the process (Dysthe, 2007) is advanced when less reliance is placed on prescribed texts. The principle underlying Web 2.0 is that students should question fixed knowledge, creating in the process a sense of shared ownership of learning (see O'Reilley, 2009). The sense of seeing others as doing the sharing, reported on above, may reflect the dislocation felt by students who did not engage in the discussions.

On the topic of the development of ability within an online learning community, the staff asserted that students should read set texts prior to engagement with others. However, this response belied a sense of distrust in the learning community's ability to create meaningful dialogue without institutionally sanctioned terms of reference. In addition, requiring students to immediately become efficient in assimilating set texts and discussing them online seems to be an unrealistic 
basis for developing dialogue. Emphasis on set texts reduces the possibility that students might be empowered during the process of studying online through the development of their sense of identity and self-efficacy. The potential for the community to develop ideas in the "rhizomatic" sense (see Cormier, 2008) through a dialogical exchange is thus undermined. According to Gulati (2004), it is within the informal/formal aspect of exchange that students can develop their own means for gathering ideas from each other (Gulati, 2004). Emergent learning is inhibited by the privileging of other, authoritative voices and student opinions that are informed by them. The centrality of the tutor in much of the discussion by students was made apparent with reference to their words being seen as "gospel" (Student, 2009). The dependence of students on the tutors for guidance might be an indication of "too little attention being paid to the learner's voice in the process of learning” (Gulati, 2004, p. 3). Gulati claims it is time for the tutor to adapt to the learner: "This includes the adaptation by the teacher, of the learner's world, through feedback on [the] learners' work and discussion” (Gulati, 2004, p. 3).

\section{The Value of Preparation in an Online Environment}

It is always easier to look in hindsight and make suggestions on how to improve the effectiveness of such a big undertaking as switching from class-based and correspondence distance learning to an online learning mode. Many more factors come into play beyond the logistics of making a new system work. Students in an online mode can have access to a far wider learning experience, particularly those who previously studied by traditional correspondence learning. The ease of communications and the combined knowledge about learning through peer group interaction has meant that the concept of what it is to learn and develop your own knowledge base has changed dramatically.

The students in this study who have been designated as strategic learners might have been strategic because they were unaware of any other approach to learning. The students' concept of learning in the programme may not have altered because previously held views that learning is individualistic, even competitive, were not addressed prior to the online experience. By not being familiar with "networked learning" the students failed to recognise the potential benefits of learning through interaction with others (Goodyear \& Yang, 2008). Is it then the role of institutions to introduce the implications for learning in a digital environment to staff and students? However, institutions cannot, or may not wish to, alter the assessment procedures integral to any award-bearing course. If institutions retain a summative approach to assessment no matter how much emphasis is laid on developing knowledge through a community of learners, ultimately this leaves the strategic learner unchallenged. This in turn would vindicate an individualistic attitude, given that the assessment remains individualistic and in turn competitive in nature.

If the online exchange was seen as an aspect of the learning outcomes, for example through processual evaluation of how the student is engaged within the learning episode, then there might be value in developing a more overt acceptance of online discussion. As there was no change in the assessment practices to match the change of mode, in this study there was little incentive for a significant number of students to move beyond a strategic approach. Marking that looks only at 
the end product and the students' ability to produce a final product runs counter to valuing engagement. The educational view of Web 2.0, the concept of emergent learning, is thus disregarded. In some ways, following the logic of this argument, the strategic learners are quite correct in their estimation of the learning task, that it is the product that is most important, not the learning process.

\section{Conclusion}

The development of Web 2.0 and open-ended learning presents tertiary education with many challenges. The scope for developing dialogue and student autonomy has important implications for institutions when shifting from a paper-based correspondence mode to an online mode. The affordance of new learning through dialogue and the scope for students to empower their own ideas and sense of ownership of their learning challenge many aspects of the learning process.

As reported in this paper, students can see learning as a chore with the best approach being to get the job done as quickly as possible. It would be a great concern if these early childhood teachers transmitted this same attitude to learning in their workplaces, and this might be a subject for subsequent study. Approaches to the discussion forum also illustrate how strategically minded students appeared to have little concept of a learning community. As a result their engagement remained tangential as references to the suitability of the forum for "others" would suggest. Again this would be a useful area to look at in more detail.

The role of the tutor was out of proportion with engagement at stage three of a degree-level course, and this might have been challenged if there had been more preparation beforehand to assuage students' fears and reduce the number of calls on the tutors for help. The very principle of the "right" answer is one that has now been overcome in most quarters of the social sciences. However, the tutors in this study did not appear to have a well-developed understanding as to how students learn through dialogue in stages. The assumption being made was that students can effectively discuss a text within a forum as a first level of engagement. This appeared to be not only unrealistic but to practically ensure that an overseer is required who can provide a clear sense of direction to the reading and learning experience. Again, this counters the sense of shared learning in the Web 2.0 context. A greater sense, therefore, of what was implied by working in the online environment may have opened up to the tutors other possibilities for how they might interact with the students and change their role when working online.

The information presented at the start of a course can effectively drive the way in which students and staff respond to the online experience. If the emphasis is on participation and giving, as opposed to individual narrowing of scope and prescribing, opportunities are afforded for lecturers and students to wholeheartedly engage in a meaningful, lasting, and at times profound exchange. Knowing what the new environment offers can lead to new realms of learning for each party (Dysthe, 2007). If the staff and students are not clear about the nature of the learning that they are engaged in, it is unlikely that a rich learning experience will eventuate. 
Despite the potential richness of the learning environment and the educational opportunities that online discussion can provide, the difficulty remains of assessment practices not being in alignment with the online context. The logic of the strategic learner defeats sharing and engagement practices when the assessment scheme is summative in nature. If the assessment were processual and the learning outcomes valued the process of learning, then further engagement by the strategic learner would be validated. The current alignment between learning tasks, experience, conditions, and assessment criteria that are summative removes participation in a learning community to the periphery of the learning process, reinforcing a strategic approach for both tutor and student. 


\section{References}

Aldrich, C. (2009). Learning online with games, simulations, and virtual worlds: Strategies for online instruction. San Francisco, CA: Jossey-Bass.

Bauman, Z. (1993). Postmodern ethics. London: Blackwell.

Biggs, J. (1993). What do inventories of students' learning process really measure? A theoretical review and clarification. British Journal of Educational Psychology, 83, 3-19.

Biggs, J., \& Tang, C. (2007). Teaching for quality learning at university. Maidenhead, UK: Society for Research into Higher Education and Open University Press.

Castells, M. (2000). The rise of the network society (2nd ed., Vol. 1). Oxford, UK: Blackwell Publishers.

Charmaz, K. (2005). Grounded theory in the 21st century: Applications for advancing social justice studies. In N. K. Denzin \& Y. S. Lincoln (Eds.), The Sage handbook of qualitative research (pp. 507-535). Thousand Oaks, CA: Sage Publications.

Cormier, D. (2008). Rhizomatic education: Community as curriculum. Retrieved from http://davecormier.com/edblog/2008/06/03/rhizomatic-education-community-ascurriculum/

Davis, B., \& Sumara, D. J. (2006). Complexity and education: Inquiries into learning, teaching and research. Mahwah, NJ: Lawrence Erlbaum Associates.

Downes, S. (2010). Stephen's Web: A series of questions. Retrieved from http://www.downes.ca/cgi-bin/page.cgi?post=52701

Driscoll, M. (2000). Psychology of learning for instruction. Needham Heights, MA: Allyn \& Bacon.

Dysthe, O. (2007). Dialogic postgraduate supervision - characteristics, constraints and affordances. University of Bergen, Norway. Retrieved from http://cc.msnscache.com/cache.aspx?q=dysthe+2007+dialogic +postgr aduate $\& d=75921804192776 \& m k t=e n-N Z \&$ setlang=en-NZ\&w=83001cbd,c5d12701

Entwhistle, N. (1981). Styles of learning and teaching: An integrated outline of educational psychology for students, teachers and lecturers. Chichester UK: John Wiley.

Fisher, T., Higgins, C., \& Loveless, A. (2006). Teachers learning with digital technologies: A review of research and projects. Bristol, UK: FutureLab. 
Goodyear, P., \& Yang, D. (2008). Patterns and pattern languages in educational design. In L. Lockyer, S. Bennett, S. Agostinho, \& B. Harper (Eds.), Handbook of research on learning design and learning objects: Issues, applications and technologies (pp. 167187). Hershey PA: Information Science Reference.

Gulati, S. (2004, April). Constructivism and emerging online learning pedagogy: A discussion for formal to acknowledge and promote the informal. Paper presented at the Annual Conference of the Universities Association of Continuing Education, University of Glamorgan.

Illich, I. (1971/2000). Deschooling society. St. Paul MN: Marion Boyars.

Kress, G., \& Pachler, N. (2007, October). Thinking about the ' $m$ ' in mobile learning. mlearn 2007, Melbourne. Retrieved from http://www.mlearn2007.org/

Lankshear, C. (2003). Wide open spaces: Wikis, ready or not. Educause Review, 39, 36-48. Retrieved from http://www.educause.edu/ir/library/pdf.erm0452.pdf

LaPointe, D. K., \& Gunawardena, C. N. (2004). Developing, testing and refining of a model to understand the relationship between peer interaction and learning outcomes in computer mediated conferencing. Distance Education, 25(1), 83-106.

Lave, J., \& Wenger, E. (1991). Situated learning: Legitimate peripheral participation. Cambridge: Cambridge University Press.

Marton, F., \& Säljö, T. (1976). On qualitative differences in learning: Outcome as a function of the learner's conception of the task. British Journal of Educational Psychology, 46, 115-127.

McWilliam, E. (2005). Unlearning pedagogy. Journal of Learning Design, 1(1), 1-11.

O’Reilley, T. (2009). What is Web 2.0? Retrieved from http://elearnspace.org/Articles/systemic_impact.htm

Roder, J., \& Hunt, T. (2009). Web 2.0 in the curriculum of the future: Exploring the educational potential of new developments in Web-based digital tools. In C. M. RubieDavies \& C. Rawlinson (Eds.), Challenging thinking about teaching and learning. New York: Nova Science Publications.

Salmon, G. (2000). E-moderating: The key to teaching and learning online. London: Kogan Page.

Siemens, G. (2008). New structures and spaces of learning: The systemic impact of connective knowledge, connectivism, and networked learning. Retrieved from http://elearnspace.org/Articles/systemic_impact.htm 
Weft Qualitative Analysis Software: http://www.pressure.to/qda/

\section{Athabasca University $\mathbf{Z}$}

(c) 